\title{
GEOMETRIC OPTIMIZATION OF "+"-SHAPED CAVITY USING CONSTRUCTAL THEORY
}

\author{
P. A. Avendaño ${ }^{\mathrm{a}}$, \\ J. A. Souza ${ }^{a}$, \\ D. F. Adamatti ${ }^{\mathbf{b}}$, \\ and E. D. Dos Santos ${ }^{a}$ \\ ${ }^{a}$ Universidade Federal do Rio Grande \\ Escola de Engenharia \\ CEP. 96203-900 \\ Rio Grande, Rio Grande do Sul, Brasil \\ pao.andrea9030@gmail.com \\ ${ }^{\text {b}}$ Universidade Federal do Rio Grande \\ Centro de Ciências Computacionais \\ CEP. 96203-900 \\ Rio Grande, Rio Grande do Sul, Brasil \\ Received: May 25, 2017 \\ Revised: June 19, 2017 \\ Accepted: July 17, 2017
}

\section{ABSTRACT}

In this work it is applied the Constructal Theory for the study of the geometry of an "+"-shaped isothermal cavity inserted in a conductive solid body. Main goal is to minimize the maximum temperature in the solid. The total volume of the solid and the total volume of the cavity are kept fixed while the dimensions of the cavity geometry vary according to constraints and degrees of freedom defined by the Constructal Design. The solid body has internal heat generation and its external surfaces are insulated. Cavity walls are isothermal with constant temperature $\mathrm{T}_{\min }$. Obtained results indicate that the optimal performance of "+"-shape cavity is $37.2 \%$ better that the optimal performance of "C"-shape cavity and $10.8 \%$ better than the " $T$ "-shaped cavity for the same thermal conditions.

Keywords: isothermal cavity, PDETool, geometric optimization, hea conduction

\section{NOMENCLATURE}

A area, $\mathrm{m}^{2}$

$\mathrm{A}_{\mathrm{c}} \quad$ cavity area, $\mathrm{m}^{2}$

$\mathrm{H}$ height, $\mathrm{m}$

$\mathrm{H}_{0} \quad$ cavity region height, $\mathrm{m}$

$\mathrm{L}$ length, $\mathrm{m}$

$\mathrm{L}_{0} \quad$ cavity region length, $\mathrm{m}$

$\mathrm{k}$ thermal conductivity, $\mathrm{W} \mathrm{m}^{-1} \mathrm{~K}^{-1}$

$\mathrm{q}$ heat current, $\mathrm{W}$

q"' volumetric rate of heat generation, $\mathrm{W} \mathrm{m}^{-3}$

$\mathrm{C}_{\mathrm{p}} \quad$ specific heat, $\mathrm{W} \mathrm{kg}^{-1} \mathrm{~K}^{-1}$

$\mathrm{t}$ time, $\mathrm{s}$

$\mathrm{T}$ temperature, $\mathrm{K}$

$\mathrm{x}, \mathrm{y} \quad$ spatial coordinates, $\mathrm{m}$

\section{Greek symbols}

$\theta \quad$ dimensionless temperature

$\rho \quad$ specific mass, $\mathrm{kg} \cdot \mathrm{m}^{-}{ }^{3}$

\section{Subscripts}

min minimum

max maximum

\section{Superscripts}

$\sim \quad$ dimensionless variables

\section{INTRODUCTION}

Constructal Theory states the fundamental idea that everything that moves, whether animate or inanimate, is a flow system. All flow systems generate shape and structure over time in order to facilitate this movement through a landscape full of resistance (e.g. friction) (Bejan, 2000; Bejan and Lorente, 2008; Bejan and Lorente, 2013 and Bejan and Zane, 2012).

In the last years, engineering problems related to the heat transfer area have received great attention. Many of these problems focus on explaining how the internal geometry of solid surfaces influences the behavior of heat transfer. They seek, in addition to understanding, to improve their performance and search for new geometries, due to the importance for various applications, such as heat exchanger, internal combustion, electric motors and thermal conductors.

Several works show the great interest that many researchers are giving to the Constructal Theory and how it is being applied in problems of optimization of the shape of flow systems that generate geometries and structures. Works such as Biserni et al. (2007), Gonzales et al. (2015), Link et al. (2013), Lorenzini et al. (2014), Lorenzini et al. (2012), Lorenzini et al. (2014), Lorenzini et al. (2011) and Lorenzini and Rocha (2009) studied isothermal cavities with different shapes intruded into solids with internal heat generation aiming to increase heat transfer, performance.

In this work, a cavity cooling problem of a steady state heat conduction solid with internal heat generation is solved with the finite element method. 
Geometry is 2D with constant physical properties (density and conductivity). Constructal Theory and Exhaustive Search are used to minimizes the maximum temperature in the solid domain. The cavity has a "+"-shaped form with constant area. Main goal of current solution is to determine best cavity geometry.

The Matlab PDETool is used to perform the different simulations. This tool is a commercial software based in the Finite Element Method (FEM) for solution of partial differential equations and it is used here to solve the heat diffusion equation for achievement of thermal field in the solid domain. In addition, it allows the construction of the computational domain from basic forms (rectangles, ellipses and polygons), generate and refine meshes and define the boundary conditions, being a useful platform to approach to this type of problem (MATLAB, 2010).

\section{MATHEMATICAL AND NUMERICAL MODELING}

In this work it, is presented a steady-state conduction heat transfer problem in which there is a two-dimensional solid (plate) with constant thermal conductivity $(\mathrm{k})$ and uniform heat generation at a volumetric rate (q"'). The solid has completely isolated boundaries and the heat generated is removed by the “+”-shaped cavity walls which are maintained at a minimum temperature $\left(\mathrm{T}_{\min }\right)$. Fig. 1 (a) shows plate, cavity and boundary conditions.

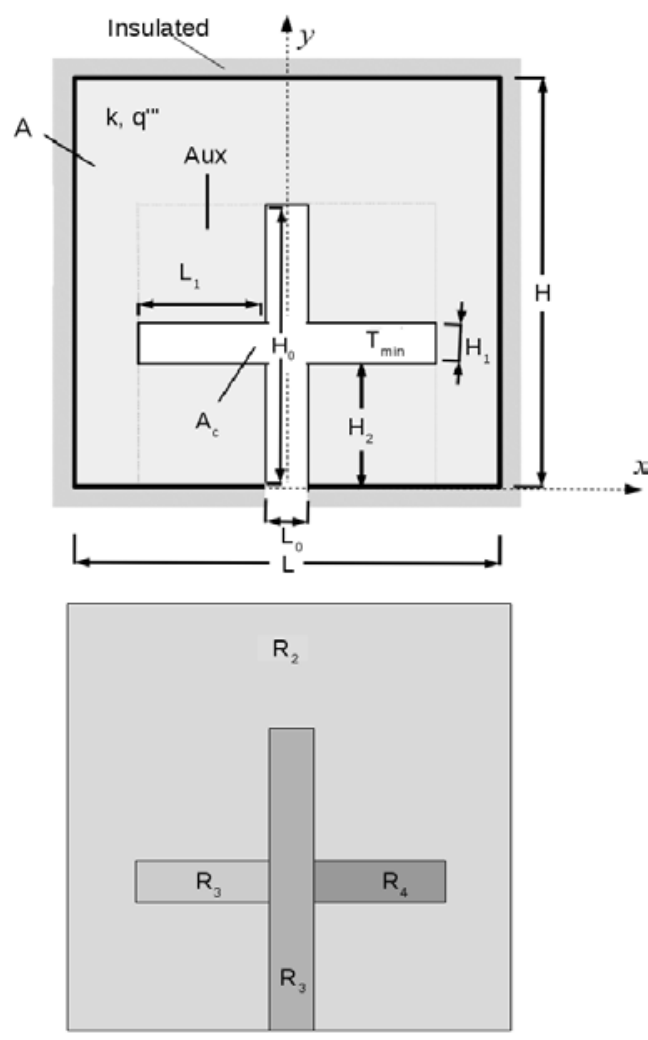

Figure 1. Problem and cavity description.
Plate has height $\mathrm{H}$ and length $\mathrm{L}$. The “+”shaped cavity can be defined as the composition of the regions $R_{2}, R_{3}$ and $R_{4}$ as shown in Fig. 1 (b), where a region $R_{2}$ has height $H_{0}$ and length $L_{0}$ and the regions $R_{3}$ and $R_{4}$ having equal dimensions being $\mathrm{H}_{1}$ the height and $\mathrm{L}_{1}$ the length. According the Constructal Theory, geometry optimization can be subject to two constraints. The first being the total area

$$
A=H \cdot L
$$

and the second corresponds to the area of the cavity which is given by

$$
A_{c}=H_{0} \cdot L_{0}+2 \cdot H_{1} \cdot L_{1}
$$

The constraints imposed by Eqs. (1) and (2) are inserted into the formulation by defining a dimensionless variable, $\varnothing$, such that

$$
\varnothing=\frac{A_{c}}{A}
$$

In addition, $\mathrm{H}_{2}$ is defined as the lower formation point of the regions $R_{3}$ and $R_{4}$.

The maximum temperature that occurs in the computational domain depends on the isothermal cavity geometry. Main goal is to optimize cavity geometry in order to minimize the dimensionless thermal resistance. The analysis that allows calculating the dimensionless thermal resistance as a function of the geometry consists of numerically solving the heat conduction equation given by

$$
k \frac{\partial^{2} \theta}{\partial \tilde{x}^{2}}+k \frac{\partial^{2} \theta}{\partial \tilde{y}^{2}}+1=0
$$

where the dimensionless variables are:

$$
\begin{gathered}
\theta=\frac{T-T_{\min }}{q^{\prime \prime} A / k} \\
\tilde{x}, \tilde{y}, \tilde{L}_{0}, \tilde{L}_{1}, \tilde{H}_{0}, \tilde{H}_{1}, \tilde{H}_{2}, \tilde{H}, \tilde{L} \\
=\frac{x, y, L_{0}, L_{1}, H_{0,} H_{1} H_{2,} H, L}{A^{1 / 2}}
\end{gathered}
$$

Dimensionless thermal resistance is defined by:

$$
\theta_{\max }=\frac{T_{\max }-T_{\min }}{q^{\prime \prime \prime} A / k}
$$

The mesh will be constructed with non-uniform triangular elements in two dimensions, having the mesh for each geometric configuration between 900 
and 45000 elements. Mesh refinement is made and validated until the criterion of grid independence is satisfied. This criterion is defined by the equation:

$$
\left(\theta_{\text {max }}^{j}-\theta_{\text {max }}^{j+1}\right) / \theta_{\text {max }}^{j}<1 \cdot 10^{-4}
$$

Table 1 shows an example of how grid independence is calculated.

Table 1. Grid independence test $(\mathrm{H} / \mathrm{L}=1, \varnothing=0.13$, $\left.\mathrm{H}_{0} / \mathrm{L}_{0}=14.26, \mathrm{H}_{1} / \mathrm{L}_{1}=0.33, \mathrm{H}_{2}=0.445\right)$.

\begin{tabular}{|c|c|c|}
\hline $\begin{array}{c}\text { Number of } \\
\text { elements }\end{array}$ & $\theta_{\text {max }}^{j}$ & $\left(\Theta_{\max }^{j}-\Theta_{\max }^{j+1}\right) / \Theta_{\max }^{j}$ \\
\hline 754 & 0.0683 & $9.54 \times 10^{-3}$ \\
\hline 3016 & 0.0690 & $3.56 \times 10^{-3}$ \\
\hline 12064 & 0.0694 & $1.41 \times 10^{-3}$ \\
\hline 48256 & 0.0695 & $5.69 \times 10^{-4}$ \\
\hline 193024 & 0.066 & \\
\hline
\end{tabular}

Conduction problem addressed needs the following boundary conditions:

- Dirichlet boundary conditions - constant surface temperature:

$$
T_{\min }=\text { const }
$$

- Neumann boundary conditions-constant thermal flux on the surface (a particular case when the surface is adiabatic or isolated as in the current problem where q" is considered equal to 0 ):

$$
-k \frac{\partial T}{\partial n}=q^{\prime \prime}
$$

Thus, by defining the external surface of the domain as adiabatic, the boundary conditions are given by the equations:

$$
\begin{gathered}
\frac{\partial \theta}{\partial \tilde{x}}=0 \text { in } \tilde{x}=-\tilde{L} / 2 \text { or } \tilde{x}=\tilde{L} / 2 \text { and } \\
0 \leq \tilde{y} \leq \tilde{H} \\
\frac{\partial \theta}{\partial \tilde{y}}=0 \text { in } \tilde{y}=0 \text { and }-\tilde{L} / 2 \leq \tilde{x} \leq-\tilde{L}_{0} / 2 \text { or } \\
\tilde{L}_{0} / 2 \leq \tilde{x} \leq \tilde{L} / 2 \\
\frac{\partial \theta}{\partial \tilde{y}}=0 \text { in } \tilde{y}=\tilde{H} \text { and }-\tilde{L} / 2 \leq \tilde{x} \leq \tilde{L} / 2
\end{gathered}
$$

Now, being

and

$$
x_{b}=\frac{\tilde{L}_{0}}{2}+\tilde{L}_{0}
$$

$$
y_{b}=\tilde{H}_{2}+\tilde{H}_{1}
$$

the boundary conditions for the cavity surface are given by

$$
\begin{gathered}
\theta=0 \text { in } \tilde{x}=-\tilde{L}_{0} / 2 \text { or } \tilde{x}=\tilde{L}_{0} / 2 \text { and } \\
0 \leq \tilde{y} \leq \tilde{H}_{2} \text { or } y_{b} \leq \tilde{y} \leq \tilde{H}
\end{gathered}
$$

$$
\begin{gathered}
\theta=0 \text { in }-x_{b} \leq \tilde{x} \leq-\tilde{L}_{0} / 2 \text { or } \tilde{L}_{0} / 2 \leq \tilde{x} \leq x_{b} \\
\text { and } \tilde{y}=\tilde{H}_{2} \text { or } \tilde{y}=y_{b} \\
\theta=0 \text { in } \tilde{x}=-x_{b} \text { or } \tilde{x}=x_{b} \text { and } \\
\tilde{H}_{2} \leq \tilde{y} \leq y_{b} \text { or } \tilde{y}=y_{b} \\
\theta=0 \text { in }-\tilde{L}_{0} / 2 \leq \tilde{x} \leq \tilde{L}_{0} / 2 \text { and } \tilde{y}=\tilde{H}
\end{gathered}
$$

Function defined by Eq. (7) can be numerically determined by solving Eq. (4) to the temperature field in each assumed configuration. Then $\theta_{\max }$ is calculated in order to study its dependence on each geometric configuration.

\section{RESULTS}

For the development of this work three degrees of freedom were considered: dimensionless values directly linked to the geometry evolution, and two constraints defined by the Constructal Design theory. The degrees of freedom considered for the "+"shaped cavity study and the definition of their appearance are: $\mathrm{H}_{0} / \mathrm{L}_{0}, \mathrm{H}_{1} / \mathrm{L}_{1}$ and $\mathrm{H}_{2}$. The defined constraints are the total area $\mathrm{A}$ and cavity area $\mathrm{A}_{\mathrm{c}}$. In addition, the dimensions of $\mathrm{H}_{0}, \mathrm{~L}_{0}, \mathrm{H}_{1}, \mathrm{~L}_{1}$ and $\mathrm{H}_{2}$ may vary, but will be restricted to maximum and minimum values, in accordance with the degree of freedom.

The search for the geometry that minimizes resistance to heat flow follows three steps. In the first one, geometry optimization is sought by varying the relation $\mathrm{H}_{0} / \mathrm{L}_{0}$ and keeping fixed the other degrees of freedom. In the second step, the relation $\mathrm{H}_{1} / \mathrm{L}_{1}$ is varied and the other parameters are kept fixed using the new value of $\mathrm{H}_{0} / \mathrm{L}_{0}$. In the third and last stage, the influence of $\mathrm{H}_{2}$ on the behavior of the temperature inside the solid is studied. For this last stage, the other degrees of freedom are kept fixed to the values obtained in the previous steps. Initially, behavior analysis of $\theta_{\max }$ are made for different cavity configurations where $\emptyset=0.13$ and $\mathrm{H} / \mathrm{L}=$ 1.0 .

In the first step simulation, it is considered the variation of ratio $\mathrm{H}_{0} / \mathrm{L}_{0}$, that defines the shape and size of the region $\mathrm{R}_{2}$ of the cavity and are kept fixed $\mathrm{H}_{1} / \mathrm{L}_{1}=0.33\left(\mathrm{H}_{1}=0.1\right.$ and $\left.\mathrm{L}_{1}=0.3\right)$ and $\mathrm{H}_{2}=$ $\left(\mathrm{H}_{0}-\mathrm{H}_{1}\right) / 2$. Constraint tested for the variation of the degrees of freedom are: $0.18 \leq \mathrm{H}_{0}<1$ and $0.07 \leq \mathrm{L}_{1}<0.4$. In Tab. 2 , it is possible to see the 
values of $\theta_{\max }$ for some values of $\mathrm{H}_{0} / \mathrm{L}_{0}$ evaluated and the amount of grid elements that previously satisfies the criterion of mesh independence.

Table 2. Optimization of $\mathrm{H}_{0} / \mathrm{L}_{0}(\emptyset=0.13, \mathrm{H} / \mathrm{L}=$ 1.0, $\mathrm{H}_{1} / \mathrm{L}_{1}=0.33$ and $\left.\mathrm{H}_{2}=\left(\mathrm{H}_{0}-\mathrm{H}_{1}\right) / 2\right)$.

\begin{tabular}{|c|c|c|}
\hline $\mathbf{H}_{\mathbf{0}} / \mathbf{L}_{\mathbf{0}}$ & Number of elements & $\boldsymbol{\theta}_{\max }$ \\
\hline 0.44 & 1416 & 0.2739 \\
\hline 7.00 & 76288 & 0.1085 \\
\hline 14.26 & 7488 & 0.066 \\
\hline
\end{tabular}

Fig. 2 shows the behavior of the maximum temperature for the different simulated configuration. It is possible to observe that the increase of the ratio $\mathrm{H}_{0} / \mathrm{L}_{0}$ leads to a decrease of maximum temperature in the domain.

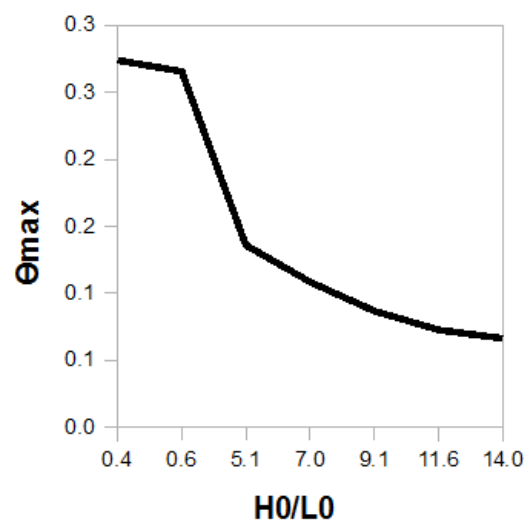

Figure 2. Effect of the ratio $\mathrm{H}_{0} / \mathrm{L}_{0}$ over the maximum temperature $\left(\theta_{\max }\right)$.

In Fig. 3, the configurations and temperature field for data presented in the Tab. 2 are shown.

For the tested configurations, $\mathrm{H}_{0} / \mathrm{L}_{0}=14.26$ presented the lowest maximum temperature. In this configuration $\mathrm{H}_{0}=0.999, \quad \mathrm{~L}_{0}=0.07 \quad$ and $\theta_{\max }=0.066$.
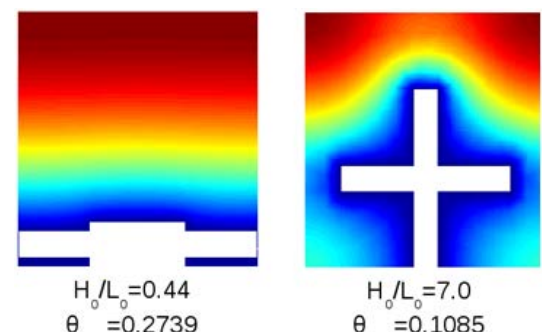

$\theta_{\max }=0.2739$

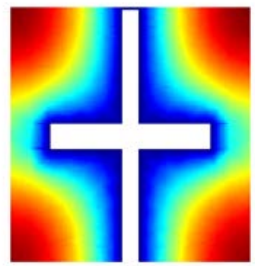

$\mathrm{H}_{0} / \mathrm{L}=7.0$

$$
\theta_{\max }=0.1085
$$

$$
\begin{gathered}
\mathrm{H}_{0} / \mathrm{L}_{0}=14.26 \\
\theta_{\max }=0.066
\end{gathered}
$$

Figure 3. Geometric configurations of different

values of $\mathrm{H}_{0} / \mathrm{L}_{0}$ ratio $(\varnothing=0.13, \mathrm{H} / \mathrm{L}=1.0$, $\mathrm{H}_{1} / \mathrm{L}_{1}=0.33$ and $\left.\mathrm{H}_{2}=\left(\mathrm{H}_{0}-\mathrm{H}_{1}\right) / 2\right)$.

In the second stage, it is performed the variation of the $\mathrm{H}_{1} / \mathrm{L}_{1}$ degree of freedom which defines the shape and size of regions $R_{3}$ and $R_{4}$ of the cavity, simultaneously. For this case, the value for the optimized $\mathrm{H}_{0} / \mathrm{L}_{0}$ ratio in the previous stage was used. Thus, the following parameters are fixed for the simulations: $\mathrm{H}_{0} / \mathrm{L}_{0}=14.26$ and $\mathrm{H}_{2}=\left(\mathrm{H}_{0}-\mathrm{H}_{1}\right) / 2$. The restrictions for the variation of tested degrees of freedom were: $0.065 \leq \mathrm{H}<0.998$ and $0.03 \leq L<$ 0.464 .

Simulation was performed for different ratios between $\mathrm{H}_{1}$ and $\mathrm{L}_{1}$ and some results are presented in Tab. 3.

Table 3. Results obtained for different values of the ratios $\mathrm{H}_{1} / \mathrm{L}_{1}\left(\varnothing=0.13, \mathrm{H} / \mathrm{L}=1.0, \mathrm{H}_{0} / \mathrm{L}_{0}=14.26\right.$ and $\left.\mathrm{H}_{2}=\left(\mathrm{H}_{0}-\mathrm{H}_{1}\right) / 2\right)$.

\begin{tabular}{llr}
\multicolumn{1}{c}{$\mathbf{H}_{\mathbf{1}} / \mathbf{L}_{\mathbf{1}}$} & Number of elements & $\boldsymbol{\theta}_{\text {max }}$ \\
0.14 & 6760 & 0.0611 \\
0.75 & 49152 & 0.0747 \\
33.2 & 21824 & 0.0877
\end{tabular}

In addition, temperature behavior is presented in Fig. 4, allowing to observe that as lower is the ratio $\mathrm{H}_{1} / \mathrm{L}_{1}$ lower is the flux resistance. Thus, the geometry which presented the best results can be seen in Fig. 5, where $\mathrm{H}_{1} / \mathrm{L}_{1}=0.14$ with $\mathrm{H}_{1}=0.065$, $\mathrm{L}_{1}=0.465$ and $\theta_{\max }=0.0611$.

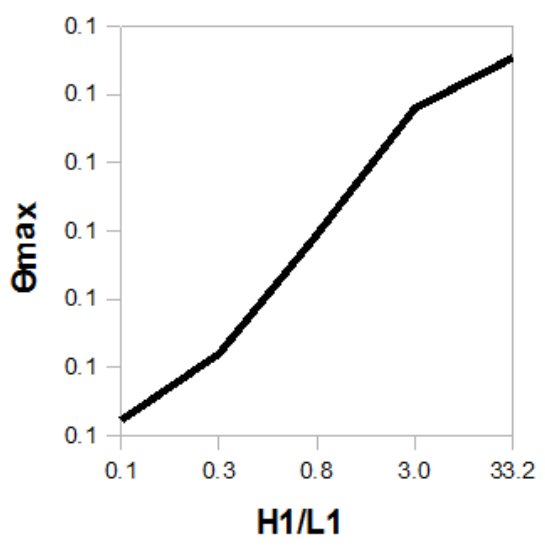

Figure 4. Behavior of $\theta \max$ for different values of $\mathrm{H}_{1} / \mathrm{L}_{1}\left(\varnothing=0.13, \mathrm{H} / \mathrm{L}=1.0, \mathrm{H}_{0} / \mathrm{L}_{0}=14.26\right.$ and $\left.\mathrm{H}_{2}=\left(\mathrm{H}_{0}-\mathrm{H}_{1}\right) / 2\right)$.

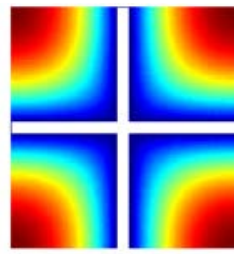

$\mathrm{H} / \mathrm{L}=0.14$ $\theta_{\max }^{1}=0.0611$

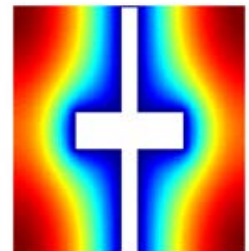

$\mathrm{H}_{1} / \mathrm{L}_{1}=0.75$ $\theta_{\max }=0.0747$ 


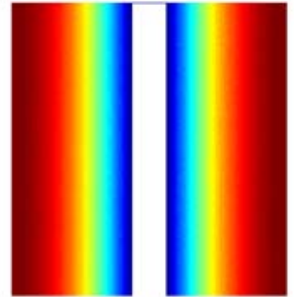

$\mathrm{H}_{1} / \mathrm{L}_{1}=33.2$

$\theta_{\max }=0.0877$

Figure 5. Some geometric configurations for different values $\mathrm{H}_{1} / L_{1}(\varnothing=0.13, \mathrm{H} / \mathrm{L}=1.0$, $\mathrm{H}_{0} / \mathrm{L}_{0}=14.26$ and $\left.\mathrm{H}_{2}=\left(\mathrm{H}_{0}-\mathrm{H}_{1}\right) / 2\right)$.

Third stage consists in evaluating the geometry considering the variation of the degree freedom $\mathrm{H}_{2}$. For this case, it was kept fixed: $\mathrm{H}_{0} / \mathrm{L}_{0}=14.26$. Third degree of freedom, $\mathrm{H}_{2}$, was made to vary from 0 to 0.93 .

Results after having solved the heat diffusion equation for different values of $\mathrm{H}_{2}$ are shown in Tab. 4 and dimensionless thermal resistance variation is plotted in Fig. 6.

Table 4. Results obtained for different values of $\mathrm{H}_{2}$ $\left(\mathrm{H}_{0} / \mathrm{L}_{0}=14.26\right.$ and $\left.\mathrm{H}_{1} / \mathrm{L}_{1}=0.14\right)$.

\begin{tabular}{|l|l|l|}
\hline \multicolumn{1}{|c|}{$\mathrm{H}_{2}$} & Number of element & $\boldsymbol{\theta}_{\max }$ \\
\hline 0.001 & 1416 & 0.0916 \\
\hline 0.2 & 6764 & 0.0839 \\
\hline $\mathbf{0 . 4 6 7}$ & $\mathbf{2 7 0 4 0}$ & $\mathbf{0 . 0 6 1 1}$ \\
\hline 0.6 & 7328 & 0.0748 \\
\hline 0.93 & 5096 & 0.0915 \\
\hline
\end{tabular}

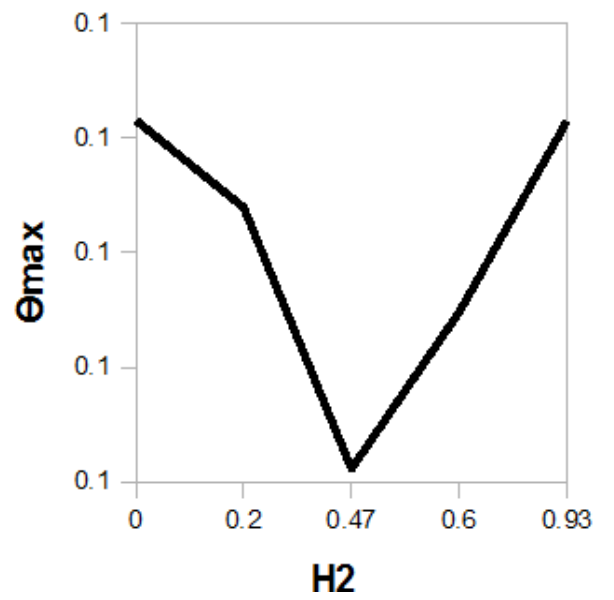

Figure 6. Behavior of $\theta_{\max }$ for different values of $\mathrm{H}_{2}\left(\mathrm{H}_{0} / \mathrm{L}_{0}=14.26\right.$ and $\left.\mathrm{H}_{1} / L_{1}=0.14\right)$.

Observing Table 4, it is clear that the configuration which leads to minimal value of $\theta_{\max }$ is obtained when $\mathrm{H}_{2}$ is such that $\mathrm{R}_{3}$ and $\mathrm{R}_{4}$ as positioned at the center of $R_{2}$ region, i.e., when $\mathrm{H}_{2}$ is close to $\left(\mathrm{H}_{0}-\mathrm{H}_{1}\right) / 2$. Thermal resistance for different values of $\emptyset$ are presented in Fig. 7

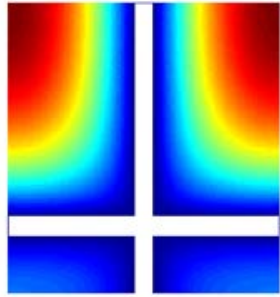

$\mathrm{H}_{2}=0.2$

$\theta_{\text {max }}=0.0839$

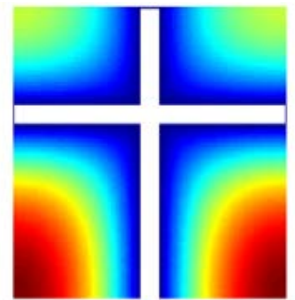

$\mathrm{H}_{2}=0.6$

$\theta_{\text {max }}=0.0748$

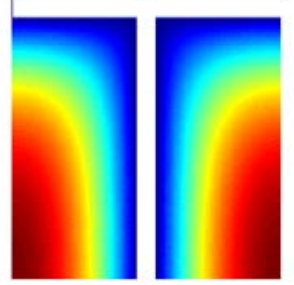

$\mathrm{H}_{2}=0.93$

$\theta_{\max }=0.0915$

Figure 7. Some geometric configurations for different values of $\mathrm{H}_{2}\left(\mathrm{H}_{0} / \mathrm{L}_{0}=14.26\right.$ and

$$
\left.\mathrm{H}_{1} / \mathrm{L}_{1}=0.14\right) \text {. }
$$

Therefore, by applying results obtained in the search for optimal cavity geometry for $\varnothing=0.13$, geometries are constructed for different ratios between the total and cavity areas. That is, the geometries are constructed by maintaining the $\mathrm{H}_{0} / \mathrm{L}_{0}$ maximum value, $\mathrm{H}_{1} / \mathrm{L}_{1}$ minimum value, and $\mathrm{H}_{2}=\left(\mathrm{H}_{0}-\mathrm{H}_{1}\right) / 2$. Results of the best geometries for $\emptyset=0.1, \emptyset=0.2$ and $\emptyset=0.3$ are shown in the Fig. 8.
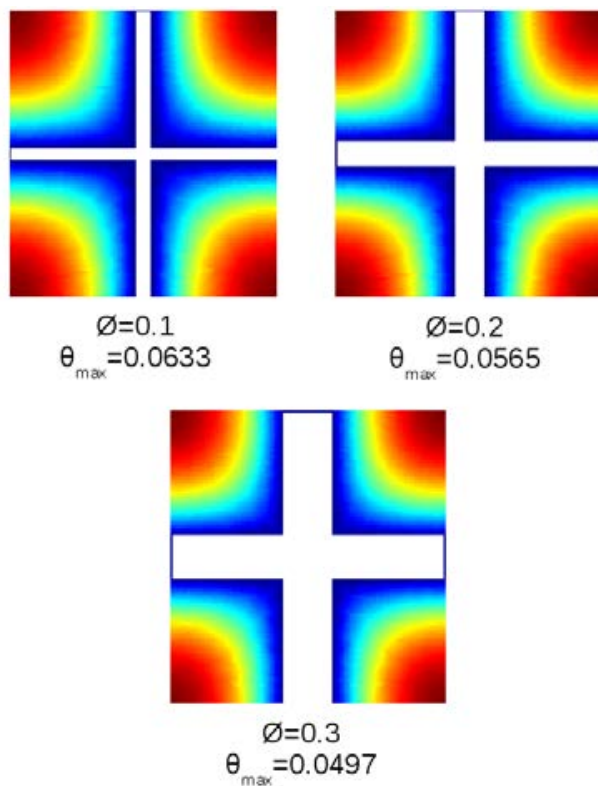

Figure 8. Best geometric configurations for $\emptyset=0.1, \emptyset=0.2$ and $\emptyset=0.3$ with $\mathrm{H} / \mathrm{L}=1.0$.

Results of this work for the $\varnothing=0.1$ and optimized C-shaped, T-shaped, H-shaped and X- 
shaped cavities were compared in Tab. 5. Results indicate that the performance of the optimum "+"shape cavity is $37.2 \%$ better than the C-shape cavity and $10.8 \%$ better than of the T-shape cavity.

Table 5. Comparison of cavities $(\mathrm{H} / \mathrm{L}=1.0$ and $\emptyset=0.1)$.

\begin{tabular}{|l|c|}
\hline & $\boldsymbol{\theta}_{\max }$ \\
\hline $\begin{array}{l}\text { C-shape cavity (Biserni, Rocha and Bejan, } \\
\text { 2004) }\end{array}$ & 0.1008 \\
\hline T-shape cavity (Lorenzini et al. 2014) & 0.0710 \\
\hline H-shape cavity (Biserni et al. 2007) & 0.0245 \\
\hline X-shape cavity (Link et al. 2013) & 0.0395 \\
\hline “+”-shape cavity & 0.0633 \\
\hline
\end{tabular}

However, it has a performance of $61.3 \%$ lower than that of the H-shape cavity and 37.6\% lower than that of the X-shape cavity.

\section{CONCLUSIONS}

In this work, a heat transfer problem was addressed in which an isothermal "+"-shaped cavity is located inside a conductive plate with heat generation. During the study, simulations were performed using the PDETool of Matlab software to study different configurations of geometry cavity, focusing on optimization, in order to minimize resistance to heat flux.

Constructal Design assists in defining the constraints and degrees of freedom of the problem geometry. The plate is insulated and with internal and a uniform heat generation. In addition, the total and cavity areas are kept constant.

Simulations were performed by varying the ratio between the geometry dimensions, optimizing one degree of freedom in each step of the process, being called "optimal" those configurations that have a lower resistance to heat flow. Results indicate that when $\varnothing=0.1$, the "+"-shape cavity has a $\theta_{\max }=0.0633$, i.e, it is $37.2 \%$ better than the optimum C-shape cavity and $10.8 \%$ better than the T-shape cavity.

In addition, the use of the Constructal Theory allows to better explain the geometric configuration that offers a better thermal performance of the system.

\section{ACKNOWLEDGEMENTS}

The authors thank CAPES to scholarship support.

\section{REFERENCES}

Bejan, A., 2000, Shape and Structure, from Engineering to Nature, Cambridge University Press.
Bejan, A., and Lorente, S., 2008, Design with Constructal Theory, Cambridge University Press.

Bejan, A., and Lorente, S., 2013, Constructal Law of Design and Evolution: Physics, Biology, Technology, and Society, Journal of Applied Physics, Vol. 113, pp. 151301-151301-20.

Bejan, A., and Zane, J. P., 2012, Design in Nature, Mechanical Engineering, Vol. 134, No. 36, pp. 42-47.

Biserni, C., Rocha, L., and Bejan, A., 2004, Inverted Fins: Geometric Optimization of the Intrusion into a Conducting Wall, International Journal of Heat and Mass Transfer, Vol. 47, pp. 2577-2586.

Biserni, C., Rocha, L., Stanescu, G., and Lorenzini, E., 2007, Constructal H-Shaped Cavities According to Bejan's Theory, International Journal of Heat and Mass Transfer, Vol. 50, pp. 2132-2138.

Gonzales, G., da SD Estrada, E., Emmendorfer, L., Isoldi, L., Xie, G., Rocha, L., and dos Santos, E., 2015, A comparison of simulated annealing schedules for constructal design of complex cavities intruded into conductive walls with internal heat generation, Energy, 93, 372-382.

Link, F. B., dos Santos, E. D., Isoldi, L. A., and Rocha, L. A. O., 2013, Constructal Design of NonUniform X-Shaped Cavity, in: International Congress of Mechanical Engineering, COBEM, Ribeirão Preto, pp. 3277-3283.

Lorenzini, G., Biserni, C., Estrada, E. d. S. D., dos Santos, E. D., Isoldi, L. A., and Rocha, L. A. O., 2014, Genetic Algorithm Applied to Geometric Optimization of Isothermal Y-Shaped Cavities, Journal of Electronic Packaging, Vol. 136, pp. 031011-031020.

Lorenzini, G., Biserni, C., Garcia, F. L., and Rocha, L. A., 2012, Geometric Optimization of a Convective T-Shaped Cavity on the Basis of Constructal Theory, International Journal of Heat and Mass Transfer, Vol. 55, pp. 6951-6958.

Lorenzini, G., Biserni, C., Link, F. B., Santos, E. D. d., Isoldi, L. A., and Rocha, L. A. O., 2014, Constructal Design of Isothermal X-Shaped Cavities, Thermal Science, Vol. 18, pp. 349-356.

Lorenzini, G., Biserni, C., and Rocha, L. A., 2011, Geometric Optimization of Isothermal Cavities According to Bejan's Theory, International Journal of Heat and Mass Transfer, Vol. 54, pp. 3868-3873.

Lorenzini, G., and Rocha, L. A. O., 2009, Geometric Optimization of T-Y-Shaped Cavity According to Constructal Design, International Journal of Heat and Mass Transfer, Vol. 52, pp. 4683-4688.

MATLAB, 2010, Version 7.10.0 (R2010a), The MathWorks Inc. 